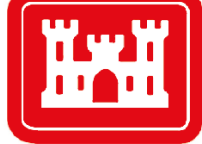

US Army Corps of Engineers ${ }_{\circledast}$

Engineer Research and

Development Center

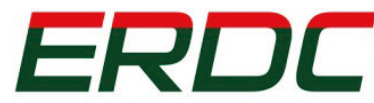

INNOVATIVE SOLUTIONS for a safer, better world

U.S. Army BT25 Basic Research Program

Flavonoids Differentially Influence Rhizosphere Bacterial Communities from Native and Introduced Lespedeza Roots

Ryan R. Busby, David B. Ringelberg, and Carina M. Jung

August 2018

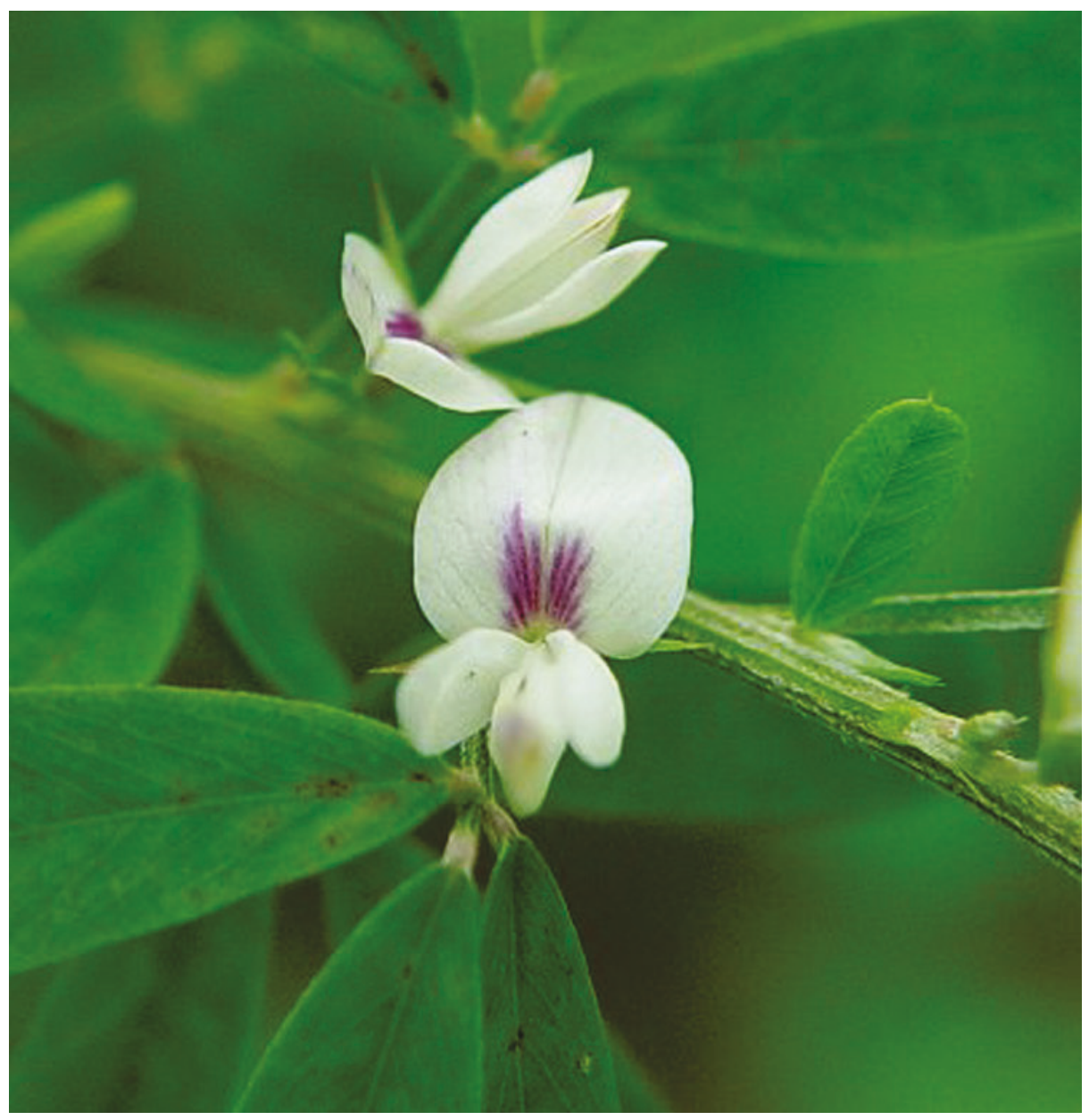


The U.S. Army Engineer Research and Development Center (ERDC) solves the nation's toughest engineering and environmental challenges. ERDC develops innovative solutions in civil and military engineering, geospatial sciences, water resources, and environmental sciences for the Army, the Department of Defense, civilian agencies, and our nation's public good. Find out more at www.erdc.usace.army.mil.

To search for other technical reports published by ERDC, visit the ERDC online library at http://acwc.sdp.sirsi.net/client/default.

Cover Photo: Closeup of Lespedeza cuneata; online image source: Invasive Species and Ecosystem Health (https://www.invasive.org/browse/subinfo.cfm?sub=3033). 


\section{Flavonoids Differentially Influence Rhizosphere Bacterial Communities from Native and Introduced Lespedeza Roots}

Ryan R. Busby

Construction Engineering Research Laboratory

U.S. Army Engineer Research and Development Center

2902 Newmark Drive

Champaign, IL 61822

David B. Ringelberg

Cold Regions Research and Engineering Laboratory

U.S. Army Engineer Research and Development Center

72 Lyme Road

Hanover, NH 03755

Carina M. Jung

Environmental Laboratory

U.S. Army Engineer Research and Development Center

3909 Halls Ferry Road

Vicksburg, MS 39180

Final report

Approved for public release; distribution is unlimited.

Prepared for Assistant Secretary of the Army (Acquisition, Logistics and Technology) 103 Army Pentagon

Washington, DC 20314-1000

Under Project 14-05, “Molecular Impact of Invasive Species Introduction on Military Lands" 


\section{Abstract}

Military training can create disturbances that facilitate invasive plant establishment. Introduced plant species' interactions with soil microbial communities through root exudates often aid plants in colonizing new locales. This study tested the hypothesis that rhizosphere bacterial communities associated with the native legume, Lespedeza virginica, and the non-native legume, Lespedeza cuneata, respond differently to plant-exuded molecules. Bacterial communities collected from coexisting populations of the two species were grown in the presence of four separate flavonoids at four concentrations. Following 96 hours of incubation, DNA was recovered from the enrichment cultures and analyzed using next-generation sequencing. In cultures receiving a flavonoid, L. virginica enrichments were characterized by a greater operational taxonomic unit (OTU) richness and exhibited a dose-response relationship to one of the flavonoids. The $L$. cuneata enrichments were characterized by a decreased OTU richness. Bacterial genera containing known pathogenic taxa occurred at a significantly greater relative frequency in L. cuneata enrichments than in the $L$. virginica enrichments. However, calculation of a species diversity index indicated greater OTU diversity in the L. cuneata enrichments across all four flavonoid treatments. These results indicate the rhizosphere microbial communities of co-existing $L$. cuneata and $L$. virginica legumes exhibit different responses when exposed to plant communication molecules.

DISCLAIMER: The contents of this report are not to be used for advertising, publication, or promotional purposes. Citation of trade names does not constitute an official endorsement or approval of the use of such commercial products. All product names and trademarks cited are the property of their respective owners. The findings of this report are not to be construed as an official Department of the Army position unless so designated by other authorized documents. 


\section{Contents}

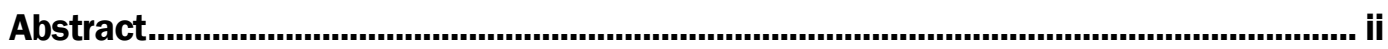

Figures and Tables....................................................................................................................

Preface

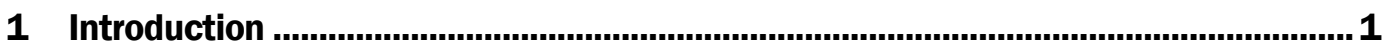

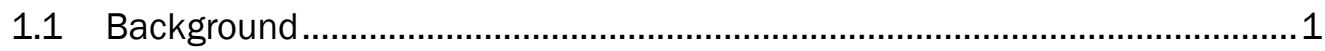

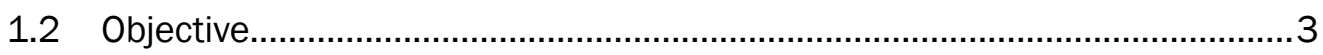

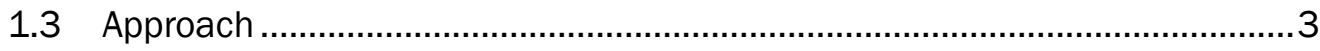

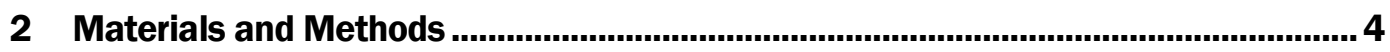

2.1 Sample collection .................................................................................. 4

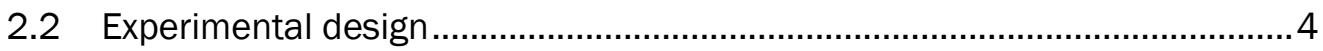

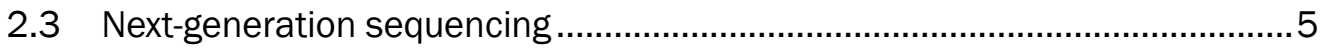

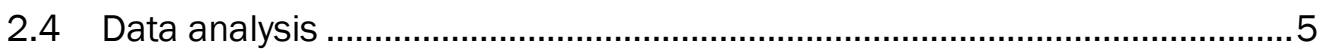

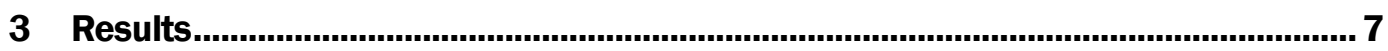

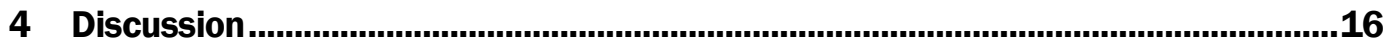

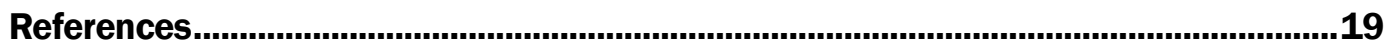

\section{Report Documentation Page}




\section{Figures and Tables}

\section{Figures}

Figure 1. Mean relative abundance of the most prevalent bacterial orders by rhizosphere source, initial rhizosphere extra, flavonoid, and concentration

Figure 2. Effects of flavonoids (a) kaempferol, (b) orientin, (c) quercetin, (d) quercitrin at varying concentrations on mean bacterial OTU richness in rhizosphere bacterial communities of $L$. cuneata and $L$. virginica. Bars represent standard errors

Figure 3. Effects of flavonoids: (a) kaempferol, (b) orientin, (c) quercetin, (d) quercitrin at varying concentrations on mean Simpson diversity indices in rhizosphere bacterial communities of L.cuneata and L. virginica. Bars represent standard errors

\section{Tables}

Table 1. Mean relative abundance of bacterial taxa identified in initial cultures of both Lespedeza cuneata and L. virginica and in post-experiment $96 \mathrm{hr}$ controls. 7

Table 2. Effects of flavonoids on mean relative frequencies of common bacterial orders. Standard errors are in parentheses.

Table 3. MRPP comparisons of bacterial OTU composition of rhizosphere bacteria associated with two plant species between flavonoids across and between different concentrations. Different letters in each column correspond to significantly different composition at the order level at an uncorrected $\mathrm{p}$ level < 0.05 . 


\section{Preface}

This work was conducted for the Assistant Secretary of the Army (Acquisition, Logistics and Technology (ASA(ALT)) under the U.S. Army Basic Research Program of PE 61102, BT25, Task 01, "Environmental Science Basic Research." The specific project covered by this report is Project 14-05, "Molecular Impact of Invasive Species Introduction on Military Lands." The technical monitor was Mr. Alan Anderson, CEERD-CZT, Technical Director for Sustainable Ranges and Lands.

The work was directed by the Ecological Processes Branch of the Installations Division (CEERD-CNN) at the U.S. Army Engineer Research and Development Center, Construction Engineering Research Laboratory (ERDCCERL). At the time of publication, Dr. Chris Rewerts was Chief, CEERDCNN, and Mr. Donald J. Hicks was Chief, CEERD-CN. The Deputy Director of ERDC-CERL was Dr. Kirankumar Topudurti, and the Director was Dr. Lance D. Hansen.

The authors wish to thank the following people for assisting in culturing the samples: Imee Smith, ERDC-CERL, and Noshin Nawar and Christopher Castle, University of Illinois.

The Commander of ERDC was COL Ivan P. Beckman, and the Director was Dr. David W. Pittman. 
[This page intentionally blank.] 


\section{Introduction}

\subsection{Background}

Introduced plant species' interactions with soil microbial communities often aid in the plants' ability to effectively colonize new locales (Callaway et al. 2004; Reinhart and Callaway 2006). These interactions include suppression of native mutualists (Vogelsang and Bever 2009), advantageous associations with native mutualists (Callaway et al. 2011; Hu et al. 2014), pathogen avoidance (Callaway et al. 2011), and facilitation of native plant pathogens (Eppinga et al. 2006). These interactions have been shown to rely on chemical signals exuded from plant roots (Nolan et al. 2014; Yuan et al. 2014). While most of these signaling chemicals have not been identified, introduced plants appear to produce greater concentrations, numbers, and species-specific secondary metabolites (Kim and Lee 2011; Macel et al. 2014). Some of the compounds identified and attributed to specific microbial responses include: benzyl- and allyl-glucosinolate, root exudates of garlic mustard, Alliaria petiolata, which impact arbuscular mycorrhizal fungi communities; the glucoside alliarinoside, which alters bacterial composition (Lankau 2011); and the flavonoid catechin, a root exudate of Centaurea stoebe (spotted knapweed) which has variable effects on bacterial communities (Pollock et al. 2011).

Plant root exudates contain a variety of chemical constituents that perform a variety of functions for the plant (Uren 2001). Individual exudate chemicals, particularly phenolic compounds, can have significant influences on the soil microbial community by selecting for different bacteria, stimulating and suppressing bacteria, and altering species richness and composition (Badri et al. 2013). Included in these compounds are the secondary metabolite flavonoids. Flavonoids are polyphenolic compounds that are ubiquitous in plants and plant tissues. Because of the variety of modifications possible to the carbon skeleton, approximately 9,000 different flavonoid molecules have been identified from plants (Ferrer et al. 2008). Flavonoids are involved in a number of important plant functions, including roles in providing adaptation to abiotic stresses and pigmentation. In soils specifically, flavonoids function to protect plants against herbivory and bacterial pathogens, aid in competitive interactions with neighboring plants, aid in communication with soil microbes, and aid in increasing nutrient availability (Shaw et al. 2006; Weston and Mathesius 2013). One of 
the primary functions of flavonoids in soils is to attract symbiotic microorganisms, including rhizobia by legumes (Aoki et al. 2000), actinomycetes by actinorhizal plants (Benoit and Berry 1997), and arbuscular mycorrhizal fungi (Siqueira et al. 1991).

Four flavonoids that have been isolated from Lespedeza spp. include kaempferol, orientin, quercetin, and quercitrin. Kaempferol and quercetin perform a variety of functions in rhizospheres, including induction of Nod genes, antibacterial activity, iron chelation, allelopathy, stimulation of mycorrhizal colonization, and nematode repellency (Ulanowska et al. 2007; Cesco et al. 2012; Weston and Mathesius 2013). Both kaempferol and quercetin are effective at disrupting quorum sensing and biofilm formation in bacterial isolates (Vikram et al. 2010). Quercetin further stimulates hyphal branching in mycorrhizal fungi and exhibits antifungal activity, while kaempferol inhibits germination of pathogenic fungal spores (Hartwig et al. 1991; Cesco et al. 2012). Isolates of Rhizobium and Pseudomonas have been observed to degrade quercetin and even utilize it as a sole carbon source (Shaw et al. 2006). Kaempferol appears to resist microbial degradation, persisting for days after clover was applied to soil as green manure and long after all other flavonoids (including quercetin) had been degraded (Carlsen et al. 2012). Much less research has been conducted on the functions of orientin and quercitrin in the plant rhizosphere. However, research investigating their roles in medicine indicates that orientin possesses antifungal properties and provides protection against radiation (Morris 2008), while quercitrin exhibits antioxidant activity (Panat et al. 2015).

Lespedeza cuneata is an introduced legume from eastern Asia (Peterson et al. 2003) and its current range in North America overlaps with numerous native Lespedeza species, including the widespread $L$. virginica (Busby et al. 2016). L. cuneata has a high polyphenol content and is associated with lower nematode densities in soils (Kardol et al. 2010). L. cuneata forms extensive stands (Yannarell et al. 2011) and benefits from greater rhizobial associations than does the native species L. virginica (Hu et al. 2014). Further, nodule-associating bacteria differ significantly in taxonomy between L. cuneata and L. virginica when coexisting in a single stand (Busby et al. 2016). The different interaction with the soil microbiological community favors establishment and growth of $L$. cuneata, which can lead to its dominance in only a few growing seasons (Coykendall and Houseman 2014). 


\subsection{Objective}

The goal of this research was to test the hypothesis that rhizosphere bacterial communities associating with the native Lespedeza virginica and nonnative Lespedeza cuneata respond differently to plant secondary metabolite communication molecules.

\subsection{Approach}

Lespedeza virginica and Lespedeza cuneata rhizosphere samples were collected from coexisting populations of the two species. Bacteria were isolated and stored for flavonoid exposure. Four flavonoids (kaempferol, orientin, quercetin, and quercitrin) were selected to represent both common and unique constituents in Lespedeza spp. Each of the four flavonoids were added separately to culture wells at concentrations of o, 50, 100 and $200 \mu \mathrm{M}$, replicated 3 times each. Each well then received $2 \mu \mathrm{L}$ of $L$. cuneata or L. virginica rhizosphere bacterial culture. Well plates were incubated at $30^{\circ} \mathrm{C}$ for $96 \mathrm{~h}$. Following incubation, $100 \mu \mathrm{L}$ of culture was recovered from each well. In addition, $100 \mu \mathrm{L}$ aliquots of the original, time zero, non-incubated bacterial cultures were recovered in a similar fashion. Recovered bacteria were sequenced using next generation sequencing with the Illumina MiSeq platform. Effects of plant, flavonoid, and flavonoid concentrations on OTU richness and diversity were analyzed, along with relative abundances of commonly occurring bacterial orders. Effects on OTU composition were analyzed using multiple response permutation procedures (MRPP). Details of the materials and methods used are in Chapter 2. 


\section{Materials and Methods}

\subsection{Sample collection}

Lespedeza virginica and Lespedeza cuneata rhizosphere samples were collected from coexisting populations of the two species in an open forest site at Fort Leonard Wood, Missouri (Busby et al. 2016). Root balls, approximately $20 \times 20 \mathrm{~cm}$ centered on the stem, were excavated in June and transported intact to the laboratory. Bulk soil was carefully removed from the roots by hand shaking. Roots were then suspended in $50 \mathrm{ml}$ of filtersterilized $0.1 \%$ sodium pyrophosphate in a $50 \mathrm{ml}$ screw-cap Falcon tube and shaken for $60 \mathrm{~min}$ at $150 \mathrm{rpm}$ and $4^{\circ} \mathrm{C}$. Tubes were allowed to stand for $2 \mathrm{~min}$ to allow large soil particles to settle out. The supernatant was then recovered using a sterile pipet, transferred to sterile $50 \mathrm{~mL}$ Falcon tubes, and centrifuged at $6,000 \mathrm{x} g$ for $7 \mathrm{~min}$ to pellet the recovered cells. The pelleted cells were washed once with DPBS (Dulbecco's phosphatebuffered saline), re-pelleted at 6,000 $\mathrm{x}$ g for $7 \mathrm{~min}$, then resuspended in $2.5 \mathrm{ml}$ of PBS (phosphate-buffered saline) containing 5\% dimethyl sulfoxide. Each cell suspension was divided into $0.5 \mathrm{~mL}$ aliquots in cryogenic vials, and frozen at $-80^{\circ} \mathrm{C}$.

\subsection{Experimental design}

Growth media consisted of $5 \mathrm{~g}$ each of glucose, peptone, tryptone, and yeast extract, and $0.6 \mathrm{~g} \mathrm{MgSO} 4{ }_{7} \mathrm{H}_{2} \mathrm{O}$, and $0.06 \mathrm{~g} \mathrm{CaCl}_{2}$ in $1 \mathrm{~L}$ deionized water. The $\mathrm{pH}$ of the media was adjusted to between 6.8 and 7.0, and then autoclaved. Autoclaved growth media $(100 \mu \mathrm{L})$ was added to each utilized well of a 96-well plate. Four flavonoids were selected to represent both common and unique constituents in Lespedeza spp. Because L. virginica phytochemistry has not been elucidated, a closely related species ( $L$. capitata) with overlapping geographical occurrence (including occurrences near the sampling location) was used as a surrogate in terms of flavonoid production. Flavonoids occurring in L. capitata include kaempferol, quercetin, and orientin (Wagner et al. 1972; Bisby et al. 1994), while flavonoids occurring in L. cuneata include kaempferol, quercetin, and quercitrin (Bisby et al. 1994; Yoo et al. 2015; Min and Shim 2016). Quercitrin is believed to be unique to L. cuneata, orientin to be unique to L. capitata, and kaempferol and quercetin are believed to be common to both species. 
Each of the four flavonoids were added separately to the respective culture wells at concentrations of $0,50,100$, and $200 \mu \mathrm{M}$, replicated 3 times each. Each well then received $2 \mu \mathrm{L}$ of $L$. cuneata or $L$. virginica rhizosphere bacterial culture. Unused wells in each plate were filled with $100 \mu \mathrm{L}$ of ultrapure water to increase humidity and prevent culture drying. Well plates were incubated at $30^{\circ} \mathrm{C}$ for $96 \mathrm{hr}$. Following incubation, $100 \mu \mathrm{L}$ of culture was recovered from each well by repeated agitation with a sterile pipette tip to dislodge any biofilm that formed on well sides. In addition, $100 \mu \mathrm{L}$ aliquots of the original, time zero, non-incubated bacterial cultures were recovered in a similar fashion. All recovered aliquots were centrifuged at $10,000 \mathrm{rpm}$ for $5 \mathrm{~min}$, the supernatant was decanted, and remaining cell pellets were frozen at $-80^{\circ} \mathrm{C}$ for sequencing.

\subsection{Next-generation sequencing}

A semi-quantitative survey method $16 \mathrm{~S}$ rDNA community analysis via next-generation sequencing with the Illumina MiSeq platform (Illumina Inc., San Diego, CA) was performed. DNA was extracted with Qiagen's Power Soil DNA Isolation Kit (Valencia, CA). Resultant DNA was amplified with uniquely barcoded primers specifically designed for 16S rRNA sequencing with the Illumina MiSeq from the 515-806 base pair (bp) region of the $16 \mathrm{~S}$ gene (E. coli numbering) (Caporaso et al. 2012). Amplicons were normalized and combined to $15 \mathrm{pmol}$ and further combined with $7.5 \%$ PhiX control, according to Illumina MiSeq instructions. The sample was added to a 300-cycle MiSeq kit for sequencing. Relative abundances of microbial community composition between samples were compared using QIIME software (Caporaso et al. 2011, 2012). Reported operational taxonomic units (OTUs) comprised at least $0.5 \%$ of the total relative abundance $(0 \%-100 \%)$, based on the total number of reads for a given sample.

\subsection{Data analysis}

Effects of plant, flavonoid, and flavonoid concentration on OTU richness were analyzed using PROC GLM in SAS software (SAS Version 9.2, SAS Institute, Cary, North Carolina). Relative abundances of individual bacterial orders with relative frequencies greater than $80 \%$ were also compared using PROC GLM in SAS. Significant differences were analyzed using Tukey's Honest Significant Difference (HSD) test at an alpha of 0.05. Simpson's Index of Diversity was calculated for each experimental unit by QIIME, using the following equation: 


$$
1-\Sigma(n / N) 2
$$

where:

$$
\begin{aligned}
& \mathrm{n}=\text { the total number of individuals for a species } \\
& \mathrm{N}=\text { the total number of individuals across all species. }
\end{aligned}
$$

Composition changes in OTUs were analyzed using MRPP in PC ORD Version 5 software (MjM Software Design, Gleneden Beach, Oregon) at the order level. Because MRPP only allows one categorical variable to be compared, concentrations were combined to observe relationships between flavonoids independent of concentration, and individual concentrations were analyzed separately to compare concentration effects within flavonoids. OTU composition was evaluated at the order level, using orders that comprised at least $5 \%$ of cells, to minimize the influence of rare species. 


\section{Results}

A total of 356 OTUs ( 355 bacteria and 1 archaea), 266 in the L. cuneata samples and 304 in the L. virginica samples, were identified in the initial rhizosphere extracts and in the post-experimental cultures. A total of 87 OTUs were found to be unique to L. cuneata and 51 to be unique to L. virginica. The initial, non-incubated, time zero rhizosphere extracts were taken from frozen stocks the day the flavonoid incubations were begun. The derived Simpson diversity index, expressed as a mean value, was found to be greater in these initial rhizosphere extracts (0.806 in L. virginica and 0.906 in L. cuneata) when compared to the 96-hour post-experimental cultures ( 0.56 in L. virginica and 0.707 in L. cuneata). The initial time zero extracts were also high in OTU richness, with mean richness values calculated at 217.5 in the $L$. cuneata isolate and 146.0 in the $L$. virginica isolate. These OTU richness values declined sharply over the time course of the experiment. The 96-hour control cultures exhibited mean OTU richness values of only 30.0 and 27.0 for L. cuneata and L. virginica, respectively. A number of bacteria orders in both plant species were observed to fall below detection limits during the laboratory incubation period (Table 1).

The three most abundant bacterial orders detected-Pseudomonadales, Enterobacteriales, and Xanthomonadales (all in the Gammaproteobacteria class)-comprised $96.3 \%$ of $L$. cuneata and $92.8 \%$ of $L$. virginica sequence reads when expressed as mean relative abundances (Figure 1). The relative abundance of these Gammaproteobacteria increased from a total of $54.9 \%$ in the initial $L$. cuneata rhizosphere extract to $99.8 \%$ in the post-experimental cultures and from $40.5 \%$ in the initial L. virginica extracts to $96.5 \%$ in the post-experimental cultures (Table 1).

Table 1. Mean relative abundance of bacterial taxa identified in initial cultures of both Lespedeza cuneata and L. virginica and in post-experiment $96 \mathrm{hr}$ controls.

\begin{tabular}{lcrlrr} 
& \multicolumn{3}{c}{ Rhizosphere Source Plant } \\
\cline { 2 - 3 } & \multicolumn{2}{c}{ Lespedeza cuneata } & & \multicolumn{2}{c}{ Lespedeza virginica } \\
\cline { 2 - 3 } \cline { 5 - 6 } & \multicolumn{2}{c}{ Relative Abundances (\%) } & & \multicolumn{2}{c}{ Relative Abundances (\%) } \\
\cline { 2 - 3 } \cline { 5 - 7 } Order & Initial & Control & & Initial & Control \\
Acidobacteriales & 1.857 & 0 & & 0.5718 & 0 \\
Actinomycetales & 0.9777 & 0 & & 3.06 & 0 \\
Alteromonadales & 0.0903 & 0.662 & & 0.0903 & 0.0135
\end{tabular}




\section{Order}

Chloroflexi TK10

Bacillales

Unclassified

Betaproteobacteria

Burkholderiales

Caulobacterales

Chromatiales

Chthoniobacterales

Enterobacteriales

Unclassified

Gammaproteobacteria

Gemmatales

Methylophilales

Nostocales

Oceanospirillales

Pseudomonadales

Rhizobiales

Rhodospirillales

Solibacterales

Solirubrobacterales

Sphingomonadales

Thermogemmatisporales

Candidate Division WPS-2

Xanthomonadales

\begin{tabular}{|c|c|c|c|}
\hline \multicolumn{4}{|c|}{ Rhizosphere Source Plant } \\
\hline \multicolumn{2}{|c|}{ Lespedeza cuneata } & \multicolumn{2}{|c|}{ Lespedeza virginica } \\
\hline \multicolumn{2}{|c|}{ Relative Abundances (\%) } & \multicolumn{2}{|c|}{ Relative Abundances (\%) } \\
\hline Initial & Control & Initial & Control \\
\hline 0.6856 & 0 & 0.0012 & 0 \\
\hline 5.905 & 0.0007 & 2.25 & 0.1157 \\
\hline 0.055 & 0 & 0.0255 & 0.0025 \\
\hline 3.055 & 0.0027 & 36.2 & 4.083 \\
\hline 1.312 & 0 & 0.64 & 0 \\
\hline 0.0005 & 0.002 & 0 & 0.002 \\
\hline 1.896 & 0 & 0.3052 & 0 \\
\hline 24.14 & 25.79 & 35.16 & 66.92 \\
\hline 0.0633 & 1.013 & 0.0109 & 0.9148 \\
\hline 1.037 & 0 & 0.365 & 0 \\
\hline 0.0019 & 0 & 0.102 & 0.0132 \\
\hline 3.005 & 0.0002 & 4.471 & 0 \\
\hline 0.0925 & 0.0074 & 0.6625 & 0.0008 \\
\hline 28.9 & 53.18 & 1.97 & 5.608 \\
\hline 7.384 & 0.0461 & 2.362 & 0 \\
\hline 2.278 & 0 & 0.46 & 0 \\
\hline 4.863 & 0.0003 & 0.3853 & 0 \\
\hline 0.996 & 0 & 0.089 & 0 \\
\hline 1.279 & 0 & 1.32 & 0 \\
\hline 0.921 & 0 & 0.0072 & 0 \\
\hline 1.316 & 0.0003 & 0.033 & 0 \\
\hline 1.48 & 19.08 & 2.545 & 22.325 \\
\hline
\end{tabular}

The mean relative abundance of Burkholderiales (class Betaproteobacteria) was found to be more than an order of magnitude greater in the initial L. virginica cultures compared to L. cuneata cultures (Figure 1), but this mean relative abundance dropped significantly in all cultures post-experimental incubation. Mean relative abundances of Enterobacteriales and Xanthomonadales were also found to be greater in the L. virginica cultures (Figure 1). The mean relative abundance of Enterobacteriales nearly doubled in the L. virginica cultures, post-experimental incubation, whereas Enterobacteriales abundance remained almost unchanged in the L. cuneata cultures. In contrast, the mean relative abundance of Xan- 
thomonadales increased significantly in both the L. virginica and L. cuneat a cultures post-experimental incubation. The mean relative abundance of Pseudomonadales was detected at a greater percentage in the L. cuneat $a$ time zero initial extracts (Figure 1). The relative abundance of the Pseudomonadales more than doubled in the L. cuneata cultures post-experimental incubation and remained relatively unchanged in the L. virginica cultures.

Figure 1. Mean relative abundance of the most prevalent bacterial orders by rhizosphere source, initial rhizosphere extra, flavonoid, and concentration.

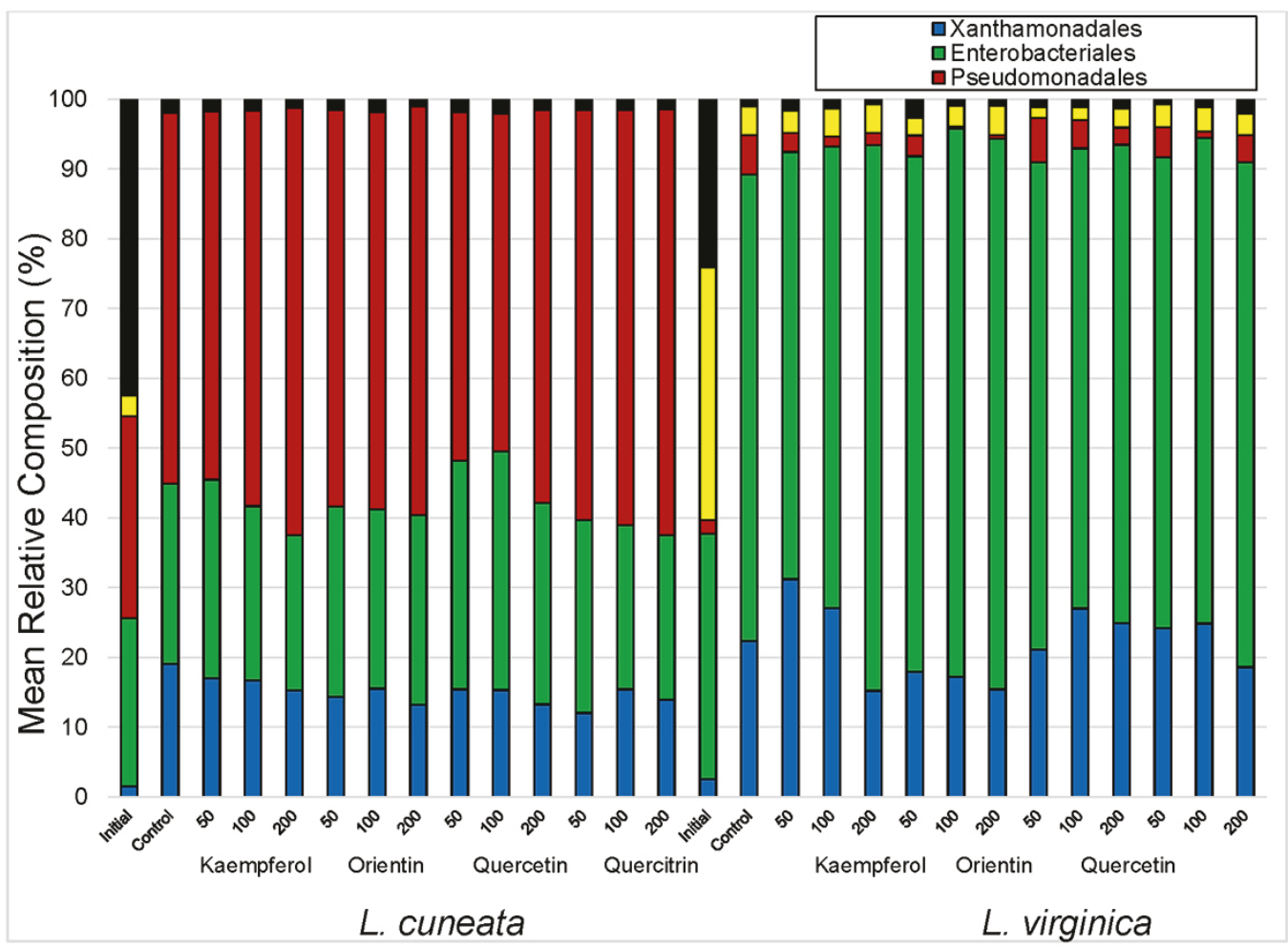

Flavonoids had a significant influence on OTU richness in the different rhizosphere bacterial communities, exhibiting a plant $\mathrm{x}$ flavonoid $\mathrm{x}$ concentration interaction $(\mathrm{F}=10.17, \mathrm{p}<0.001)$. Mean OTU richness in the $L$. cuneata cultures decreased $5 \%$ relative to the control, but increased $41 \%$ in the $L$. virginica cultures. OTU richness in the L. cuneata-associated bacterial communities responded negatively to kaempferol and orientin (Figure $2 \mathrm{a}$ and Figure 2b), exhibited a dose-specific response to quercetin (Figure 2c), and exhibited no response to quercitrin (Figure 2d). Likewise, OTU richness in the L. virginica-associated bacterial community exhibited dose-specific responses to kaempferol and orientin (Figure 2a and Figure 
2b), exhibited no response to quercetin (Figure 2c), and exhibited a strong positive response to quercitrin (Figure 2d).

Figure 2. Effects of flavonoids (a) kaempferol, (b) orientin, (c) quercetin, (d) quercitrin at varying concentrations on mean bacterial OTU richness in rhizosphere bacterial communities of $L$. cuneata and $L$. virginica. Bars represent standard errors.
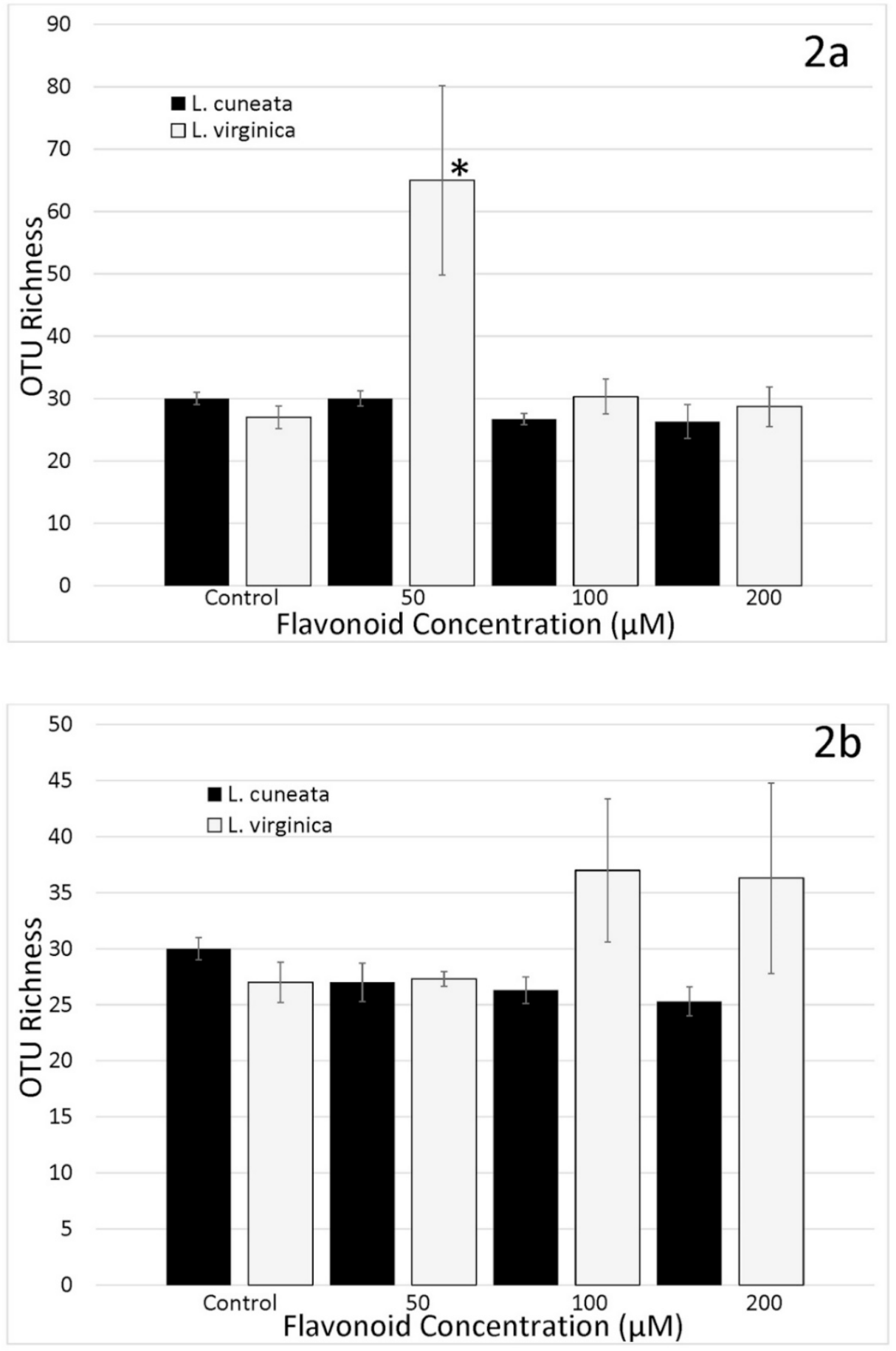

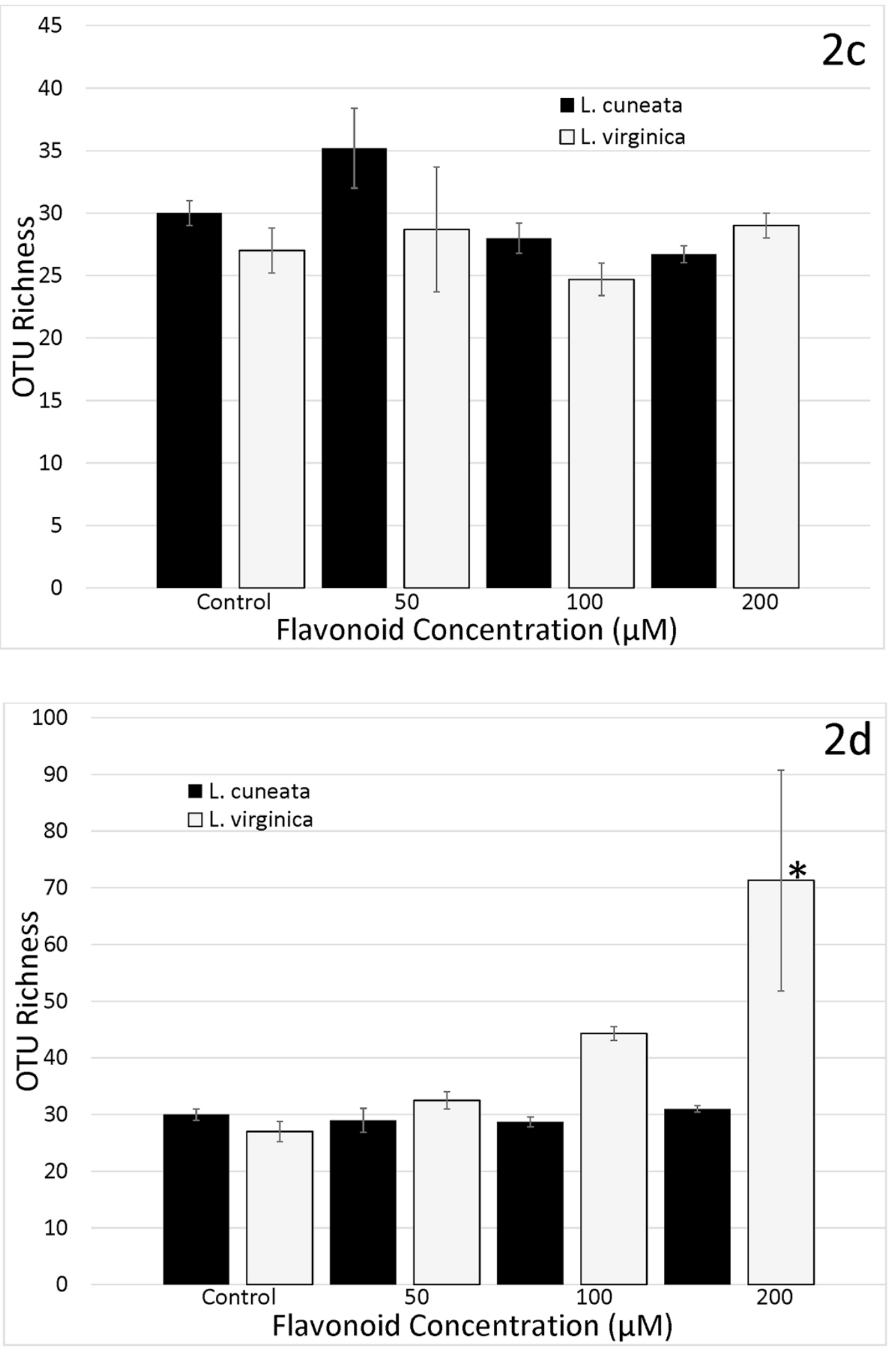
Plant $(\mathrm{F}=132.6, \mathrm{p}<0.001)$ and flavonoid type $(\mathrm{F}=4.57, \mathrm{p}<0.01)$ had a significant effect on Simpson diversity in the post-incubation cultures (Figure 3a-d). Diversity decreased with increasing kaempferol (Figure 3a), orientin (Figure 3b), and quercitrin (Figure 3c) concentrations for both plant rhizosphere sources. Quercetin concentrations had little effect on diversity from either rhizosphere source (Figure $3 \mathrm{~d}$ ). Analyses revealed that both plant $(\mathrm{F}=31.82, \mathrm{p}<0.0001)$ and flavonoid type $(\mathrm{F}=3.17, \mathrm{p}=0.03)$ affected the relative frequency of Xanthomonadales (Table 2). Within L. cuneata treatments, Burkholderiales exhibited a flavonoid $\mathrm{x}$ concentration effect $(\mathrm{F}=3.71, \mathrm{p}<0.01)$. Flavonoid type alone was found to have a significant effect on Enterobacteriales $(\mathrm{F}=4.72, \mathrm{p}<0.01)$ and Burkholderiales ( $\mathrm{F}=4.66, \mathrm{p}<0.01$ ), but only in the L. virginica cultures (Table 2 ).

Table 2. Effects of flavonoids on mean relative frequencies of common bacterial orders. Standard errors are in parentheses.

\begin{tabular}{|c|c|c|c|}
\hline \multirow[b]{3}{*}{ Flavonoid } & \multicolumn{3}{|c|}{ Rhizosphere Source } \\
\hline & \multicolumn{2}{|c|}{ L. virginica } & \multirow{2}{*}{$\begin{array}{l}\text { Lespedeza combined } \\
\text { Xanthomonadales }\end{array}$} \\
\hline & Enterobacteriales & Burkholderiales & \\
\hline None & $66.92(1.16)$ & $4.08(1.87)$ & $20.7(1.37)$ \\
\hline Kaempferol & $68.55(2.98)$ & $3.78(0.28)$ & $20.39(1.77)$ \\
\hline Orientin & 77.13 (2.61) & $3.24(0.34)$ & $15.61(1.31)$ \\
\hline Quercetin & $68.15(1.32)$ & $2.05(0.23)$ & $19.49(1.57)$ \\
\hline Quercitrin & $70.1(1.6)$ & $3.32(0.23)$ & $17.81(1.51)$ \\
\hline
\end{tabular}

Flavonoids also had a significant effect on community composition (Table 3). Quercitrin treatments with $L$. cuneata cultures resulted in a unique bacterial community that differed from those associated with all the other flavonoids $(\mathrm{A}=0.09, \mathrm{p}=0.03$ vs. kaempferol; $\mathrm{A}=0.08, \mathrm{p}<0.05$ vs. orientin; $A=0.14, p=0.01$ vs. quercitrin). Within the $L$. virginica cultures, the presence of orientin resulted in a unique bacterial community that differed from all other flavonoids $(\mathrm{A}=0.09, \mathrm{p}<=0.05 \mathrm{vs}$. kaempferol; $\mathrm{A}=$ $0.19, \mathrm{p}<0.01$ vs. quercetin; $\mathrm{A}=0.09, \mathrm{p}=0.04$ vs. quercitrin). 
Figure 3. Effects of flavonoids: (a) kaempferol, (b) orientin, (c) quercetin, (d) quercitrin at varying concentrations on mean Simpson diversity indices in rhizosphere bacterial communities of L.cuneata and L. virginica. Bars represent standard errors.

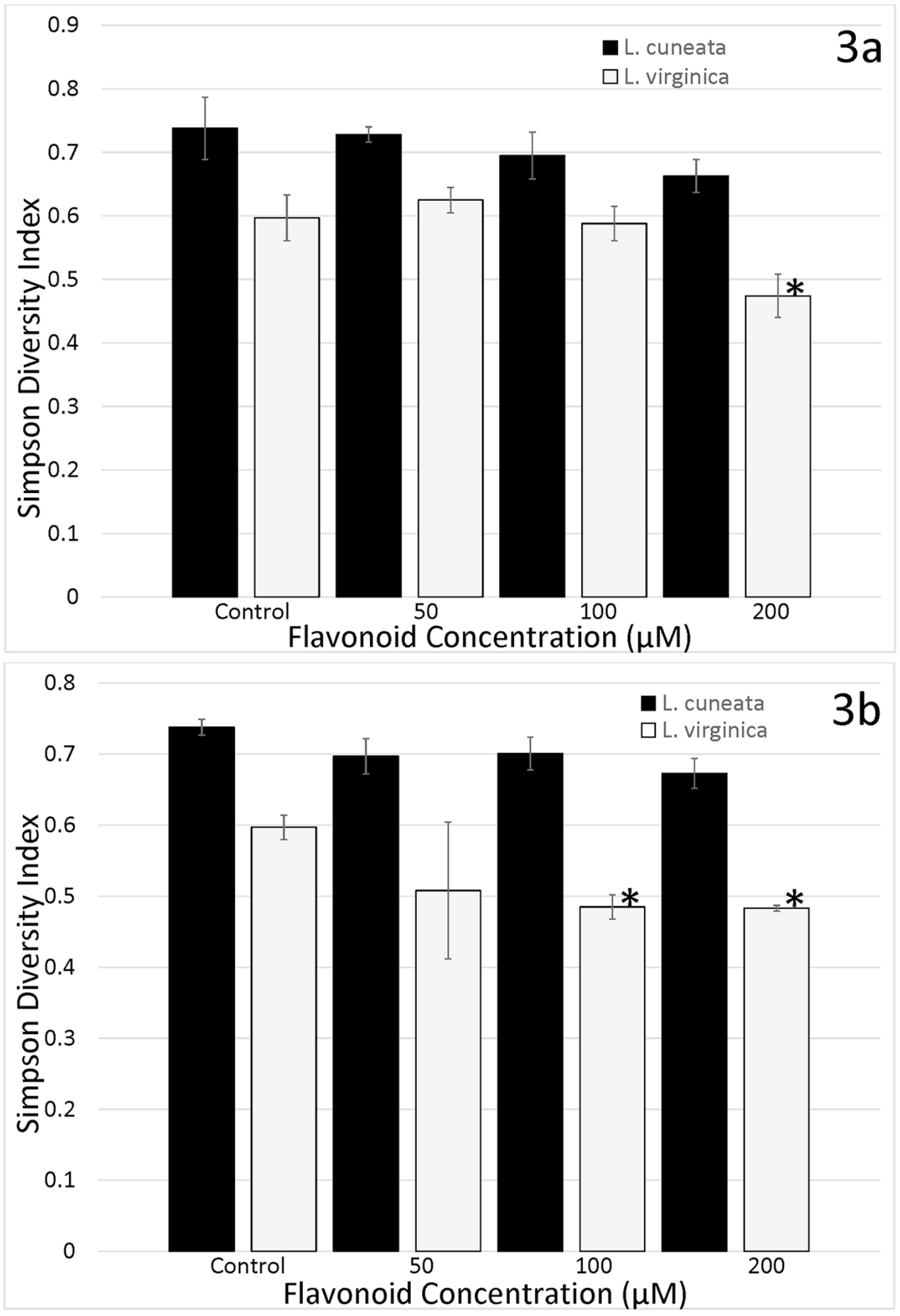




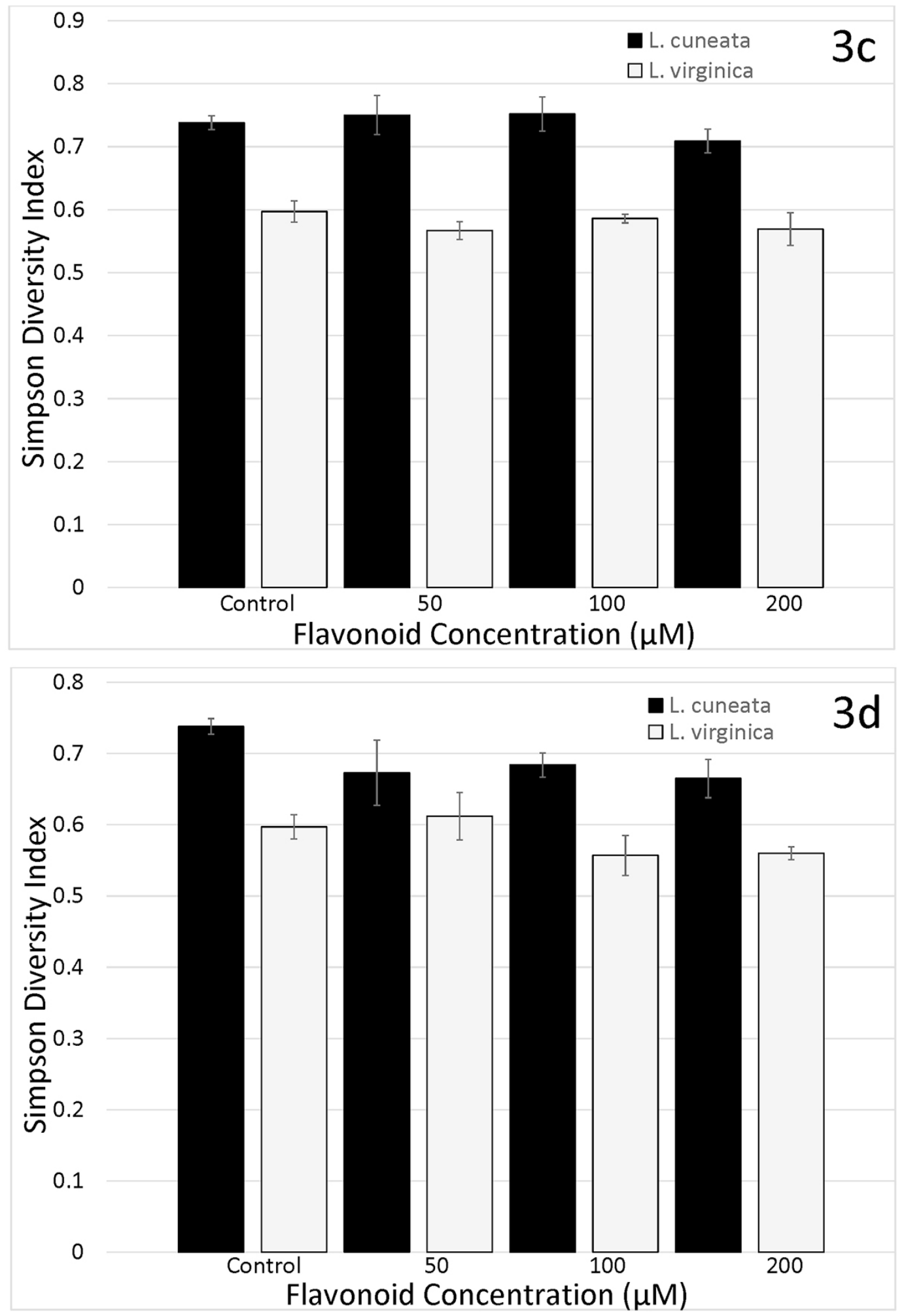


Table 3. MRPP comparisons of bacterial OTU composition of rhizosphere bacteria associated with two plant species between flavonoids across and between different concentrations. Different letters in each column correspond to significantly different composition at the order level at an uncorrected $\mathrm{p}$ level $<0.05$.

\begin{tabular}{|l|c|c|c|c|c|c|c|c|}
\hline \multirow{2}{*}{ Flavonoid } & \multicolumn{2}{|c|}{ All Concentrations } & \multicolumn{2}{c|}{$50 \mu \mathrm{M}$} & \multicolumn{2}{c|}{$100 \mu \mathrm{M}$} & \multicolumn{2}{c|}{$200 \mu \mathrm{M}$} \\
\cline { 2 - 10 } & L. cuneata & L. virginica & L. cuneata & L. virginica & L. cuneata & L. virginica & L. cuneata & L. virginica \\
\hline Kaempferol & B & B & A & A & AB & B & A & AB \\
\hline Orientin & B & A & A & AB & AB & A & A & B \\
\hline Quercetin & A & B & A & B & A & B & A & A \\
\hline Quercitrin & B & B & A & B & B & AB & A & A \\
\hline
\end{tabular}




\section{Discussion}

We failed to reject our hypothesis that rhizosphere bacterial communities associating with the native Lespedeza virginica and non-native L. cuneata legumes would respond differently to plant communication molecules. Our results identified a decline in mean OTU richness in $L$. cuneata rhizosphere cultures following exposure to increasing concentrations of kaempferol, orientin, and quercetin, but no response to quercitrin. Quercetin was associated with a unique $L$. cuneata-derived bacterial community that differed in composition from all other flavonoids. Mean OTU richness in L. virginica cultures was found to be more variable than observed in L. cuneata; the variation increased significantly with increasing quercitrin concentration, showed specific positive dose responses to kaempferol and orientin, and had no response to quercetin. Orientin was associated with a unique $L$. virginica-derived bacterial community that differed in composition from all of the other flavonoids. The dose-specific responses observed in L. virginica cultures indicate a Goldilocks effect for these flavonoids on the studied bacterial community, where too little has no measurable effect and too much has a suppressive effect. This effect has been observed in previous research, where some flavonoids increased biological activity with increasing concentrations, while others peaked and then declined (Begum et al. 2001; Ulanowska et al. 2007). These previous studies also found high variability between bacterial responses to different flavonoids at the individual bacterial isolate level.

Invasive plant species have been shown to alter the bacterial community in invaded soils compared to native plants (Batten et al. 2006; Swedo et al. 2008; Bray et al. 2017). A previous study observed that $L$. cuneata benefits from greater rhizobial associations than does the native species, L. virginica (Hu et al. 2014); this observation supports the advantageous associations with native mutualists' hypothesis of plant invasion (Callaway et al. 2011). Other previous research observed that nodule-associating bacteria differ significantly in taxonomy between invasive and native species when they were coexisting in a single stand. Burkholderiales has been observed in Lespedeza nodules; however, the family Burkholderiaceae occurred exclusively in native Lespedeza nodules, while the family Comamonadaceae, which includes the pathogenic bacteria Acidovorax, occurred exclusively 
in L. cuneata (Busby et al. 2016). These prior findings support the "facilitation of native plant pathogens hypothesis" of plant invasion (Eppinga et al. 2006).

In this study, the four bacterial orders found to differ significantly between the two rhizosphere sources were further broken up into pathogenic genera, based on Agrios (2005) and compared to OTU alignments in the cultures. Richness of these pathogenic genera were virtually identical between the two plant rhizospheres; however, the relative abundance of these pathogenic genera was much higher in the $L$. cuneata initial extracts and cultures, when compared to L. virginica. This finding provides further support for the facilitation of native plant pathogens hypothesis of plant invasion.

Within the Enterobacteriales, Serratia (a genus of common plant pathogens) was predominant in L. cuneata cultures, while Citrobacter (a nonpathogenic genus) was predominant in L. virginica cultures. A similar result was observed with respect to the Pseudomonadales, where Pseudomonas (a genus of common plant pathogens) was predominant in L. cuneata cultures, while Acinetobacter (a genus of non-pathogens) was predominant in L. virginica cultures. The Xanthomonadales (an order containing many common bacterial pathogens) was comprised primarily of OTUs aligned most closely with the genus Stenotrophomonas, a group of bacterial species not known to be pathogenic but rather to function as plant growth promoters (Ryan et al. 2009). This genus was much more prevalent, in terms of relative OTU abundance, in association with $L$. virginica than L. cuneata. While both Pseudomonas and Serratia contain pathogens, they also contain plant growth-promoting bacteria (Preston 2004; Zaheer et al. 2016). These observations both lend support to the facilitation of the native plant pathogens hypothesis and suppression of the native mutualists' hypotheses of plant invasion (Vogelsang and Bever 2009).

Unfortunately, at the level of resolution for our data and with only two initial rhizosphere extracts compared, it cannot be stated that pathogens were higher in association with L. cuneata compared to L. virginica or that native mutualists were suppressed in the presence of the invasive species. Results from this study did identify that genera with no known pathogenic species were higher in relative abundance in association with $L$. virginica compared to $L$. cuneata within the most common bacterial orders, while genera with known pathogenic species were much higher in 
relative abundance in association with $L$. cuneata compared to L. virginica within the most common bacterial orders. Thus, it is unknown if the mutualists associating with the native Lespedeza were suppressed by the invader, outcompeted by more aggressive pathogens, or absent for other reasons. Additional research using a greater number of rhizosphere samples and higher sequencing resolution to identify bacterial species would determine whether these observed trends could potentially support a prevailing hypothesis for plant invasion using two (and possibly more) congeners with overlapping ranges.

Because no data was available regarding $L$. virginica flavonoid exudates, L. capitata exudates were used instead. While it is possible that the exudates used are not produced by L. virginica, it is equally possible that all four flavonoids are produced by both Lespedeza species, but these species have not been fully characterized yet. In legume species that have been more fully characterized, all four of these flavonoids do occur together, for instance, in Onobrychis vicifolia (Regos et al. 2009) and in Desmodim canadense (Puodziunene et al. 2009), a common native legume that overlaps both with $L$. virginica's native range and the invaded range of $L . c u$ neata.

Results of this study demonstrate that rhizosphere bacteria communities isolated from native and introduced congeners from a common location differ in their composition and responses to flavonoid exposure. Flavonoid type influenced bacterial community responses, as a function of the unique plant rhizosphere. Further, the native plant rhizosphere maintained higher bacterial richness when flavonoids were present, while the introduced plant rhizosphere lost richness and was observed to have increased abundances of genera containing known pathogens. However, the introduced plant rhizosphere maintained greater bacterial diversity in the presence of flavonoids compared to the native plant rhizosphere. These findings indicate that the studied rhizosphere communities are highly variable and differentially responsive to added plant communication molecules, and that the invader associates with a more diverse rhizosphere bacterial community that is less responsive to flavonoids. 


\section{References}

Agrios, G.N. 2005. Plant Pathology, 5th edition. Amsterdam: Elsevier.

Aoki T,, T. Akasaki, S. Ayabe. 2000. "Flavonoids of Leguminous Plants: Structure, Biological Activity and Biosynthesis.” Journal of Plant Research 113(4):475-488.

Badri, D.V., J.M. Chaparro, R. Zhang, Q. Shen, and J.M. Vivanco. 2013. “Application of Natural Blends of Phytochemicals Derived from the Root Exudates of Arabidopsis to the Soil Reveals that Phenolic-Related Compounds Predominantly Modulate the Soil Microbiome." The Journal of Biological Chemistry 288(7):4502-4512.

Batten, K.M., K.M. Scow, K.F. Davies, and S.P. Harrison. 2006. "Two Invasive Plants Alter Soil Microbial Community Composition in Serpentine Grasslands.” Biological Invasions 8(2):217-230.

Begum, A.A., S. Leibovitch, P. Migner, and F. Zhang. 2001. "Specific Flavonoids Induced Nod Gene Expression and Pre-Activated Nod Genes of Rhizobium leguminosarum Increase Pea (Pisum sativum L.) and Lentil (Lens culinaris L.) Nodulation in Controlled Growth Chamber Environments." Journal of Experimental Botany 52:1537-1543.

Benoit, L., and A. Berry. 1997. "Flavonoid-like Compounds from Seeds of Red Alder (Alnus rubra) Influence Host Nodulation by Frankia (Actinomycetales)." Physiologia Plantarum 99(4):588-593.

Bisby, F.A., J. Buckingham, and J.B. Harbone. 1994. "Phytochemical Dictionary of the Leguminosae." In Volume 1: Plants and their Constituents. London: Chapman and Hall.

Bray, S.R., A.M. Hoyt, Z. Yang, and M.A. Arthur. 2017. "Non-Native Liana, Euonymus fortunei, Associated with Increased Soil Nutrients, Unique Bacterial Communities, and Faster Decomposition Rate.” Plant Ecology 218(3):329-343.

Busby R.R., G. Rodriguez, D.L. Gebhart, and A.C. Yannarell. 2016. "Native Lespedeza Species Harbor Greater Non-Rhizobial Bacterial Diversity in Root Nodules Compared to the Coexisting Invader, L. cuneata." Plant and Soil 401(1-2):427436.

Callaway, R.M., G.C. Thelen, A. Rodriguez, and W.E. Holben. 2004. "Soil Biota and Exotic Plant Invasion.” Nature 427:731-733.

Callaway, R.M., E.J. Bedmar, K.O. Reinhart, C.G. Silvan, and J.Klironomos. 2011. "Effects of Soil Biota from Different Ranges on Robinia Invasion: Acquiring Mutualists and Escaping Pathogens." Ecology 92(5):1027-1035.

Caporaso, J.Gregory, Christian L. Lauber, William A. Walters, Donna Berg-Lyons, J. Huntley, Noah Fierer, S.M. Owens, J. Betley, L. Fraser, M. Bauer, N. Gormley, J.A. Gilbert, G. Smith, G., and Rob Knight. 2012. "Ultra-High-Throughput Microbial Community Analysis on the Illumina HiSeq and MiSeq Platforms." ISME Journal 6(8): 1621-1624. doi: 10.1038/ismej.2012.8. 
Caporaso, J. Gregory, Christian L. Lauber, William A. Walters, Donna Berg-Lyons, Catherine A. Lozupone, Peter J. Turnbaugh, Noah Fierer, and Rob Knight. 2011. "Global Patterns of 16S rRNA Diversity at a Depth of Millions of Sequences per Sample." Proceedings of the National Academy of Sciences of the United States of America 108 (Supplement 1): 4516-4522. https://doi.org/10.1073/pnas.1000080107.

Cesco, S., T. Mimmo, G. Tonon, N. Tomasi, R. Pinton, R. Terzano, G. Neumann, L. Weisskopf, G. Renella, L. Landi, and P. Nannipieri. 2012. "Plant-Borne Flavonoids Released into the Rhizosphere: Impact on Soil Bio-Activities Related to Plant Nutrition: A Review." Biology and Fertility of Soils 48(2):123-149.

Coykendall, K.E., and G.R. Houseman. 2014. "Lespedeza cuneata Invasion Alters Soils Facilitating Its Own Growth.” Biological Invasions 16(8):1735-1742.

Eppinga, M.B., M. Rietkerk, S.C. Dekker, P.C. De Ruiter, and W.H. Van der Putten. 2006. "Accumulation of Local Pathogens: A New Hypothesis to Explain Exotic Plant Invasions." Oikos 114(1):168-176.

Ferrer, J-L., M.B. Austin, C. Stewart Jr, and J.P. Noel. 2008. "Structure and Function of Enzymes Involved in the Biosynthesis of Phenylpropanoids." Plant Physiology and Biochemistry 46(3):356-370.

Hartwig, U.A., C.M. Joseph, and D.A. Phillips. 1991. "Flavonoids Released Naturally from Alfalfa Seeds Enhance Growth Rate of Rhizobium meliloti." Plant Physiology 95(3):797-803.

Hu, L., R.R. Busby, D.L. Gebhart, and A.C. Yannarell. 2014. "Invasive Lespedeza cuneata and Native Lespedeza virginica Experience Asymmetrical Benefits from Rhizobial Symbionts." Plant and Soil 384(1-2):315-325.

Kardol, P., M.A. Cregger, C.E. Campany, A.T. Classen. 2010. "Soil Ecosystem Functioning under Climate Change: Plant Species and Community Effects." Ecology 91(3):767-781.

Kim, Y.O., and E.J. Lee. 2011. "Comparison of Phenolic Compounds and the Effects of Invasive and Native Species in East Asia: Support for the Novel Weapons Hypothesis." Ecological Research 26(1):87-94.

Lankau, R.A. 2011. "Intraspecific Variation in Allelochemistry Determines an Invasive Species' Impact on Soil Microbial Communities.” Oecologia 165(2):453-463.

Macel, M., R.C.D. de Vos, J.J. Jansen, W.H. van der Putten, and N.M. van Dam. 2014. "Novel Chemistry of Invasive Plants: Exotic Species have More Unique Metabolomic Profiles than Native Congeners." Ecology and Evolution 4(13): 2777-2786.

Min, J.Y., and S.H. Shim. 2016. "Chemical Constituents from Lespedeza cuneata G. Don (Leguminosae).” Biochemical Systematics and Ecology 66:293-296.

Morris, J.B. 2008 "Rhynchosia minima (L.) DC. - Regeneration, Characterization and Potential Uses for Natural Products and Flavonoids.” Plant Genetic Resource Newsletter 153:15-19. 
Nolan, N. E., A. Kulmatiski, N.H. Beard, and J.M. Norton. 2014. "Activated Carbon Decreases Invasive Plant Growth by Mediating Plant-Microbe Interactions." AoB PLANTS Vol. 7. doi:10.1093/aobpla/pluo72.

Panat, N.A., B.K. Amrute, S. Bhattu, S.K. Haram, G.K. Sharma, and S.S. Ghaskadbi. 2015. "Antioxidant Profiling of $\mathrm{C}_{3}$ Quercetin Glycosides: Quercitrin, Quercetin 3- $\beta$-DGlucoside and Quercetin 3-O-(6"-O-malonyl)- $\beta$-D-Glucoside in Cell-Free Environment." Free Radicals and Antioxidants 5(2):90-100.

Peterson, A.T., M. Paper, and D.A. Kluze. 2003. "Predicting the Potential Invasive Distributions of Four Alien Plant Species in North America." Weed Science 51(6):863-868.

Pollock, J.L., L.A. Kogan, A.S. Thorpe, and W.E. Holben. 2011. “( \pm )-Catechin, a Root Exudate of the Invasive Centaurea stoebe Lam. (Spotted Knapweed) Exhibits Bacteriostatic Activity against Multiple Soil Bacterial Populations.” Journal of Chemical Ecology 37:1044-1053.

Preston, G.M. 2004. "Plant Perceptions of Plant Growth-Promoting Pseudomonas." Philosophical Transactions: Biological Sciences 359(1446):907-918.

Puodziunene, G., V. Janulis, L. Ivanauskas, A. Lukosius, Z. Barsteigene, V. Ribokaite. 2009. "Quantitative Estimation of Flavonoids in the Vegetative and Reproductive Organs of Showy Tick Trefoil (Desmodium canadense)." Pharmaceutical Chemistry Journal-USSR 43:324-327.

Regos, I., A. Urbanella, and D. Treutter. 2009. "Identification and Quantification of Phenolic Compounds from the Forage Legume Sainfoin (Onobrychis vicifolia)." Journal of Agricultural and Food Chemistry 57(13):5843-5852.

Reinhart, K.O., and R.M. Callaway. 2006. "Soil Biota and Invasive Plants.” New Phytologist 170(3):445-457.

Ryan, R.P., S. Monchy, M. Cardinale, S. Taghavi, L. Crossman, M.B. Avison, G. Berg, D. van der Lelie, and J.M. Dox. 2009. "The Versatility and Adaptation of Bacteria from the genus Stenotrophomonas." Nature Reviews Microbiology 7(7):514525 .

Shaw, L.J., P. Morris, and J.E. Hooker. 2006. "Perception and Modification of Plant Flavonoid Signals by Rhizosphere Microorganisms.” Environmental Microbiology 8(11):1867-1880.

Siqueira, J.O., G.R. Safir, and M.G. Nair. 1991. "Stimulation of Vesicular-Arbuscular Mycorrhizal Fungi Formation and Growth of White Clover by Flavonoid Compounds." New Phytologist 118(1): 87-93.

Swedo, B.L., C. Glinka, D.R. Rollo, and H.L. Reynolds. 2008. "Soil Bacterial Community Structure under Exotic versus Native Understory Forbs in a Woodland Remnant in Indiana." Proceedings of the Indiana Academy of Science 117(1):7-15.

Ulanowska, K., A. Majchrzyk, M. Moskot, J. Jakóbkiewicz-Banecka, and G. Węgrzyn. 2007. "Assessment of Antibacterial Effects of Flavonoids by Estimation of Generation Times in Liquid Bacterial Cultures." Biologia, Bratislave, Section Cellular and Molecular Biology 62(2):132-135. 
Uren, N.C. 2001. "Types, Amounts, and Possible Function of Compounds Released into the Rhizosphere by Soil-Grown Plants." In The Rhizosphere: Biochemistry and Organic Substances at the Plant-Soil Interface (p 19-40), edited by R. Pinton, Z. Varanini, and P. Nannipieri. New York: Marcel Dekker.

Vikram, A., G.K. Jayaprakasha, P.R. Jesudhasan, S.D. Pillai, B.S. Patil. 2010. "Suppression of Bacterial Cell-Cell Signalling, Biofilm Formation, and Type III Secretion System by Citrus Flavonoids." Journal of Applied Microbiology 109(2):515-527.

Vogelsang, K.M., and J.D. Bever. 2009. "Mycorrhizal Densities Decline in Association with Nonnative Plants and Contribute to Plant Invasion.” Ecology 9o(2): 399407 .

Wagner, H., M. A. Iyengar, and L. Hörhammer. 1972. "Flavonoids in Lespedeza capitata." Phytochemistry 11(4):1518.

Weston, L.A., and U. Mathesius. 2013. "Flavonoids: Their Structure, Biosynthesis and Role in the Rhizosphere, Including Allelopathy." Journal of Chemical Ecology $39(2): 283-297$.

Yannarell, A.C., R.R. Busby, M.L. Denight, D.L. Gebhart, and S.J. Taylor. 2011. "Soil Bacteria and Fungi Respond on Different Spatial Scales to Invasion by the Legume Lespedeza cuneata." Frontiers in Microbiology 2:127. doi 10.3389/fmicb.2011.00127.

Yoo, G., S.J. Park, T.H. Lee, H. Yang, Y. Baek, N. Kim, Y.J. Kim, and S.H. Kim. 2015. "Flavonoids Isolated from Lespedeza cuneata G. Don and Their Inhibitory Effects on Nitric Oxide Production in Lipopolysaccharide-Stimulated BV-2 Microglia Cells." Pharmacognosy Magazine 11(43):651-656.

Yuan, Y., J. Tang J, D. Leng, S. Hu, J.W.H. Yong, and X. Chen. 2014. “An Invasive Plant Promotes Its Arbuscular Mycorrhizal Symbioses and Competitiveness through Its Secondary Metabolites: Indirect Evidence from Activated Carbon." PLOS One 9(5):e97163. doi:10.1371/journal.pone.0097163.

Zaheer, A., B.S. Mirza, J.E. Mclean, S. Yasmin, T.M. Shah, K.A. Malik, and M.S. Mirza. 2016. "Association of Plant Growth-Promoting Serratia spp. with the Root Nodules of Chickpea." Research in Microbiology 167(6):510-520. 


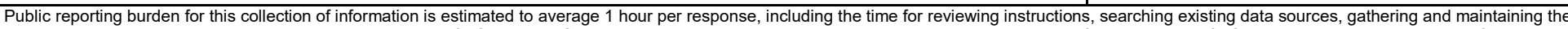

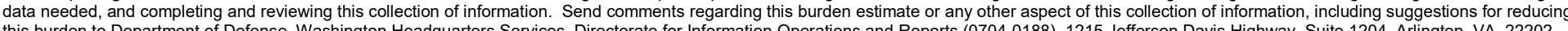

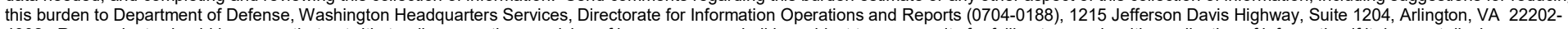

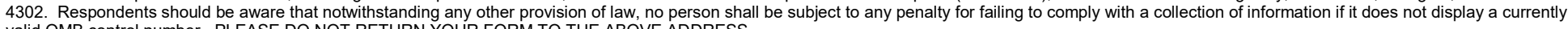
valid OMB control number. PLEASE DO NOT RETURN YOUR FORM TO THE ABOVE ADDRESS
1. REPORT DATE (DD-MM-YYYY)
2. REPORT TYPE
August 2018
Final

\section{TITLE AND SUBTITLE}

Flavonoids Differentially Influence Rhizosphere Bacterial Communities from Native and Introduced Lespedeza Roots

5a. CONTRACT NUMBER

5b. GRANT NUMBER

5c. PROGRAM ELEMENT NUMBER

BT25

6. AUTHOR(S)

Ryan R. Busby, David B. Ringelberg, and Carina M. Jung

5d. PROJECT NUMBER

14-05

5e. TASK NUMBER

01

5f. WORK UNIT NUMBER

7. PERFORMING ORGANIZATION NAME(S) AND ADDRESS(ES)

U.S. Army Engineer Research and Development Center (ERDC)

Construction Engineering Research Laboratory (CERL)

8. PERFORMING ORGANIZATION REPORT NUMBER

PO Box 9005

Champaign, IL 61826-9005

ERDC TR-18-10

\section{SPONSORING / MONITORING AGENCY NAME(S) AND ADDRESS(ES)}

Assistant Secretary of the Army (Acquisition, Logistics and Technology)

103 Army Pentagon

Washington, DC 20314-1000

10. SPONSOR/MONITOR'S ACRONYM(S)

ASA(ALT)

11. SPONSOR/MONITOR'S REPORT NUMBER(S)

12. DISTRIBUTION / AVAILABILITY STATEMENT

Approved for public release. Distribution is unlimited.

\section{SUPPLEMENTARY NOTES}

\section{ABSTRACT}

Military training can create disturbances that facilitate invasive plant establishment. Introduced plant species' interactions with soil microbial communities through root exudates often aid plants in colonizing new locales. This study tested the hypothesis that rhizosphere bacterial communities associated with the native legume, Lespedeza virginica, and the non-native legume, Lespedeza cuneata, respond differently to plant-exuded molecules. Bacterial communities collected from coexisting populations of the two plant species were grown in the presence of four separate flavonoids at four concentrations. Following 96 hours of incubation, DNA was recovered from the enrichment cultures and analyzed using next-generation sequencing. In cultures receiving a flavonoid, L. virginica enrichments were characterized by a greater OTU richness and exhibited a dose-response relationship to one of the flavonoids. The L. cuneata enrichments were characterized by a decreased OTU richness. Bacterial genera containing known pathogenic taxa occurred at a significantly greater relative frequency in $L$. cuneata enrichments than in the L. virginica enrichments. However, calculation of a species diversity index indicated greater OTU diversity in the L. cuneata enrichments across all four flavonoid treatments. These results indicate that the rhizosphere microbial communities of coexisting L. cuneata and L. virginica legumes exhibit different responses when exposed to plant communication molecules.

\section{SUBJECT TERMS}

Military training, Invasive plants, Plant-soil relationships, Microbial ecology, Lespedeza cuneata, Flavonoids

\section{SECURITY CLASSIFICATION OF:}

a. REPORT

Unclassified b. ABSTRACT

Unclassified

17. LIMITATION
OF ABSTRACT
UU

\begin{tabular}{|c|}
$\begin{array}{c}\text { 18. NUMBER } \\
\text { OF PAGES }\end{array}$ \\
\cline { 2 - 2 } 31
\end{tabular}

19a. NAME OF RESPONSIBLE PERSON

19b. TELEPHONE NUMBER (include area code) 